\title{
DEMOGRAPHIC, SOCIAL AND ORGANIZATIONAL CHARACTERISTICS ON THE LEVELS OF MOBBING AND SINGLE CASES OF HARASSMENT: THE MULTICOMPLEX APPROACH
}

\author{
Jolita Vveinhardt, Dalia Štreimikienè
}

\section{Introduction}

Understanding of the reasons of destructive relationships in work environment is a big step towards the solution of the problem. In recent years, there are a growing number of studies which analyse various aspects of such relations in the work environment. Mobbing and harassment take a significant place. However, when analysing academic literature, there is a dual problem: in many studies mobbing and single cases of harassment are researched separately. On the one hand, harassment often receives attention when researching the attacks of sexual nature, and also by demographic, occupational criteria, the criterion of the impact on the victim, etc. (Muliawan \& Kleiner, 2001; Huang \& Cao, 2008; Salin, 2009; Ford, 2013; etc.), on the other hand, harassment is analysed in the context of a certain system of negative actions - mobbing, when psychological trauma is caused, the problems of managerial work, etc. arise (Einarsen, 1999; Mathisen et al., 2012; Beirne \& Hunter, 2013; etc.). It can be argued that single cases of harassment are a symptom indicating the existence of mobbing in the organization, but it would be difficult to find an ideal organization, which managed to completely avoid the single cases of harassment. Therefore, the question of when and under what conditions the existing harassment threatens to grow into mobbing is relevant. The answers to this question can be presented by the complex analysis of the problem, and the complexity of the approach provides more benefits, e.g. developing prevention strategies or providing recommendations for executives of the organizations. According to Zapf (1999), one-sided explanations on the causes of mobbing are likely to be inappropriate and that many cases are characterized by multicausality. However, the studies often analyse mobbing in employees' relations at one or more certain layers: demographic (JohnsonBailey, 2014; O'Donnell \& Maclntosh, 2015), area of professional activity (Riley et al., 2011; Casimir et al., 2012), organizational (Hogh et al., 2011; Citoni et al., 2012), sector, e.g. public sector (Hogh et al., 2011), nature of damage (Hoel et al., 2002; Carnero et al., 2012), the strategy of overcoming (Cooper-Thomas et al., 2013; Karatuna, 2015) and many more. Some examples of how the problem is analysed wider than in one or two aspects can be distinguished. Citoni et al. (2012) in their research provide new evidence regarding the impact of work organization (essentially defined in terms of payment methods, teamwork, workforce age structure and labour contracts) on performance (measured through employment, productivity and sickness absenteeism indicators). Although this and other studies note social, organizational and demographic criteria, there is a lack of studies, which analyse cases of both mobbing and harassment. Therefore, this research aimed to look at the problem of destructive relations between employees in the organization from the multi-complex point of view.

The purpose of this article is distinguishing between the employees who experienced mobbing and single cases of harassment, to analyse demographic, social and organizational characteristics of the phenomena, in order to form a multi-complex approach.

Only the results of the research of those who have experienced mobbing and single 
cases of harassment are analysed. It allows to deeper research not only the characteristics of the victim, but also the specifics of the organization where the victim works, and the ways to help the victims, i.e. whether the organization takes appropriate measures after identification of the problem or leaves the solution to develop spontaneously. This condition is especially important in organization of corporate governance, in order to avoid mobbing and single cases of harassment. The originality of the research is determined by the fact that not only mobbing is analysed, but also the situation of single cases of harassment in organizations, distinguishing between the two phenomena. The aim of the distinguishing and comparison is to determine to what extent and in what cases the existence of single cases of harassment warns that it can expand and turn into mobbing. Due to the representatives of different professional activities we can form the general view and highlight the most vulnerable areas of professional activity in respect of the phenomena analysed. The fact that the survey of the employees was carried out in the country, which is considered to be an economically developing country should also be noted. It can create additional conditions for the conflicts to arise and/or become deeper in employees' relations. The research is original as it analyses the phenomena of mobbing and single cases of harassment showing a wide range of sociodemographic characteristics, i.e., through such components of the victim as age, length of service, gender, marital status, education, the position in the company. The analysis is also performed through such organizational components as belonging to a certain sector (public, private), areas of professional activity, the size of the company in accordance with the number of employees, etc. This research further identifies gaps in previous research; in addition, it puts forward an agenda for future research in this area.

\section{Literature Review}

\section{Mobbing and Harassment}

Mobbing in this research is defined as an organized long-lasting and intense attack on the victim in the workplace. According to Zapf (1999), mobbing is defined as a severe form of social stressors at work. This is the actions carried out systematically and for a long time by one or more collaborators and/or executives, when the victim is unable to defend himself/ herself or to change the situation (Leymann, 1990; Zapf, 1999; Einarsen, 1999; Salin, 2003; etc.). Single cases of harassment in this research are defined as organized or unorganized attack on the victim that does not fall into the range of time and duration ascribable to mobbing. Harassment is discussed as any co-worker's action causing psychological and/ or physical damage. It is discriminatory sexual (Macdermott, 1995; Daigle \& Mummert, 2014) and not only sexual physical and non-physical violence in various forms, brutal behaviour with colleagues (Brodsky, 1976; Chrobot-Mason et al., 2013; Holt et al., 2014; etc.). In addition, the authors draw attention to cultural factors, which determine the fact that both the victims and the aggressors in individual cultures perceive the actions of harassment differently when comparing individual cultural groups (Stedham \& Yamamura, 2004; Adikaram, 2014; Jacobson et al., 2014; etc.). This means that the diagnostic instruments of mobbing and harassment should be reviewed in respect of each culture individually.

\section{Age, Length of Service and Mobbing/ /Harassment}

The research, which would have found the direct link with the length of service and mobbing is not abundant. Mauno et al. (2011), who researched the problems of opportunities to get a permanent job in the health sector, noted the fact that the length of service can become a positive factor. D'Cruz and Rayner (2013) in the research carried out in India, found the connection between the years of work experience and higher positions in the hierarchy of the company. In other words, length of service and employees' experience has an influence on career, however, the results of the research, relating length of service with mobbing, are not unambiguous, though the connection is observable (Kaya et al., 2012). A direct connection between mobbing and length of service was established by Ertürk and Cemaloğlu (2014). The research was carried out in the educational system and the trend that employees with a length of service from 13 to 24 years suffer from mobbing more than those whose length of service is up to 12 years was observed. Another research has received opposite results after surveying the employees of sports institutions: it turned out that the 
employees who had the length of service of 1-10 years were mobbed more than others (Hacicaferoglu et al., 2012). Nevertheless, a number of studies show that older employees suffer from mobbing more frequently (Niedl, 1995; Einarsen, 2005), and demography and relations between the generations influence the occurring conflicts (Zemke et al., 2000).

\section{Gender and Mobbing/Harassment}

In the analysis of the causes of mobbing carried out by Zapf (1999) gender is not a significant factor. Unlike the context of sexual harassment, where sexuality is one of the major risk factors for destructive behaviour of colleagues (SedivyBenton et al., 2014; Johnson-Bailey, 2014), based on the cultural approach to masculinity and femininity (Koeszegi et al., 2014). On the other hand, the men who experienced harassment avoid complaining about the problems (O'Donnell \& Macintosh, 2015). Salin and Hoel (2013) found, that there are gender differences not only in reported prevalence rates and forms of bullying, but that gender also matters for the way targets and third parties make sense of and respond to bullying. It is shown that gendered conceptions of power, gender role socialisation theory and social identity theory are all relevant for explaining reported gender differences.

Personal life, gender and level of education may be targets, to which the attack is directed, but the results of studies are quite ambiguous. The results of the research carried out by Einarsen and Skogstad (1996) in various organizations show that even if men and women do not differ in prevalence of bullying, significantly more men were reported as bullies. Picakciefe et al. (2015) carried out the research only in health care organizations and state that there has not been a significant difference among those with a different gender, age group, educational level, and the presence of income other than salary and occupation, when the encountered with "mobbing" in the workplace was evaluated. According to the authors, the frequency of encountering with "mobbing" was found significantly meaningful in married health workers. Previously Moreno-Jiménez et al. (2008) stated, that women and the employees who have lower education face a greater risk of suffering the aggression, but with respect to marital status, hierarchical status, work schedule and age the analyses did not show any significant differences. However, Yildirim et al. (2007) research shows that a lower status in organizational hierarchy causes a higher risk to experience mobbing.

Many studies are limited to individual groups of organizations in the private or public sectors. However, the studies show that there is a higher the risk of experiencing mobbing in the public sector (Hutchinson \& Jackson, 2015). Based on Hutchinson (2012), while many of the workplace bullying risk factors such as organizational change, job insecurity and work intensification exist within the private sector, the majority of international research highlights bullying in the public sector (Hutchinson, 2012). In addition, organizations with many employees, male-dominated organizations, and industrial organizations had the highest prevalence of victimization (Einarsen \& Skogstad, 1996), bullying also seems more prevalent in SMEs without a people-oriented culture and in family businesses (Baillien et al. 2011).

\section{Results}

Organization of the research. The research sample includes 21 fields of professional activity. The fields of professional activity are grouped according to the Classification of Economic Activities. In the survey 1,231 respondents who experienced attacks in employees' relations took part. 867 respondents have indicated that they had experienced mobbing (out of 1,231 respondents). Other 364 participants of the survey have experienced single cases of harassment.

Results of the research. In this part the results of the research, which reflect mobbing and single cases of harassment situations separately are presented and compared. Mobbing and harassment can be distinguished methodologically, as those who experience mobbing always experience harassment, but those who experience harassment not always experience mobbing (Žukauskas \& Vveinhardt, 2013), however, a part of intense pressure in respect of time can be shorter than six months. It is significant to take into account that the environment full of harassment may lead to the occurrence of mobbing; therefore, the group of risk was distinguished when elaborating the results of the research. The research has shown that about one-fifth of the victims have suffered one of the criteria distinguished by Leymann (1993) that is, they were terrorized at 
least once a week, but the attack has not yet reached a six-month term.

Thus, two-thirds of the respondents suffered attacks not less frequent than once a week. A significantly larger number of victims were harmed for half a year and for a longer period. It shows a notably wide circle of victims, which are aggressively attacked, although this attack does not necessarily correspond to the classic definition of mobbing. Therefore, the actual occurrence of mobbing could be statistically higher. It is shown by the explanations of some victims who had experienced long-term attacks of co-workers, but of unequal frequency.

Some victims commented that they got into helpless situations periodically, depending on the circumstances related to the organization of work, for example, such as shift work, leading to a meeting with the harasser. That is, the harasser has not always been in the direct working environment, but the victim felt the threat and tension. The named individual situations can be considered to be variables, which do not allow classifying part of the victims as the ones who experience mobbing in accordance with the classical definition of mobbing.

According to Fitzpatrick (2011), research on workplace mobbing by vocational scholars could lead to a better understanding of individual career development and improved worker interventions. The occurrence of mobbing depending on the length of employment and age is presented in Fig. 1 and Fig. 2.

\section{Fig. 1: Percentage distribution of respondents' answers according to the length of employment}

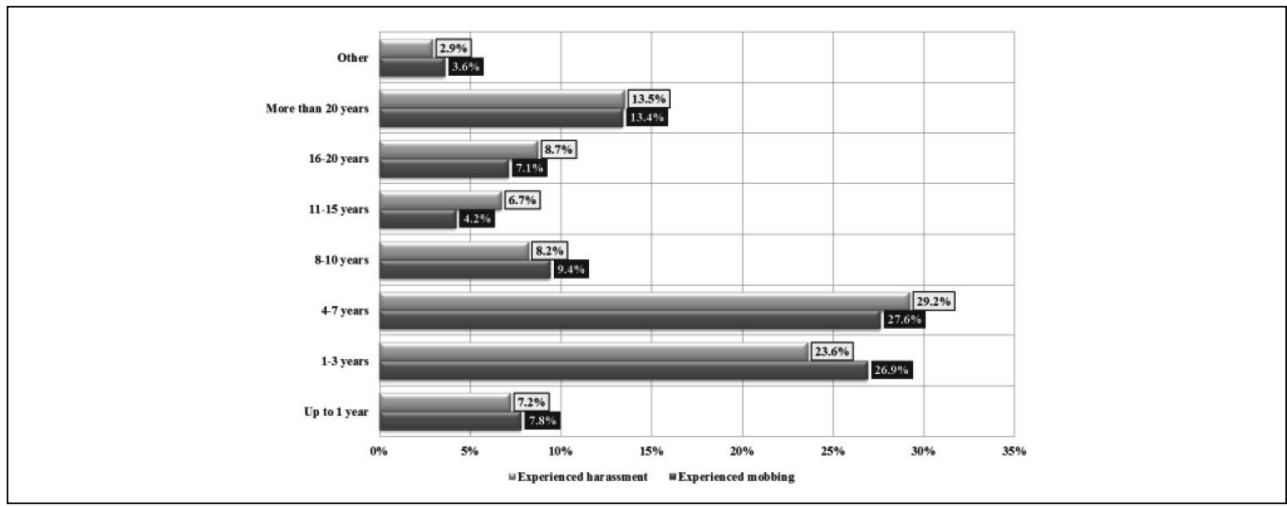

Source: own

\section{Fig. 2: Percentage distribution of respondents' answers according to the age}

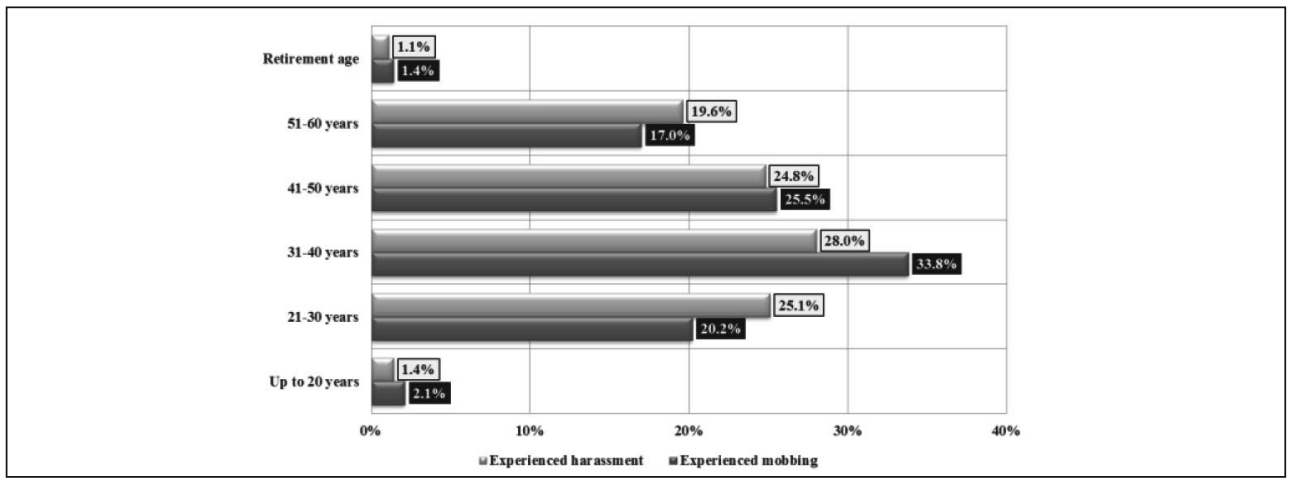


Thus, the biggest risk is at the beginning of a career, and when professional maturity is reached. The tendencies in mobbing and harassment within groups remain similar, although at the beginning of a career (from 1 to 3 years) and up to 20 years of age mobbing is significantly more likely to be suffered. The tendencies of the age of the victims shown basically reflect the results of the research conducted by Niedl (1995) that employees older than 61 had been chosen as victims more often. Comparing the attacks by gender and marital status, the differences between harassment and mobbing are insignificant (Fig. 3 and Fig. 4).

\section{Fig. 3: Percentage distribution of respondents' answers according to their gender}

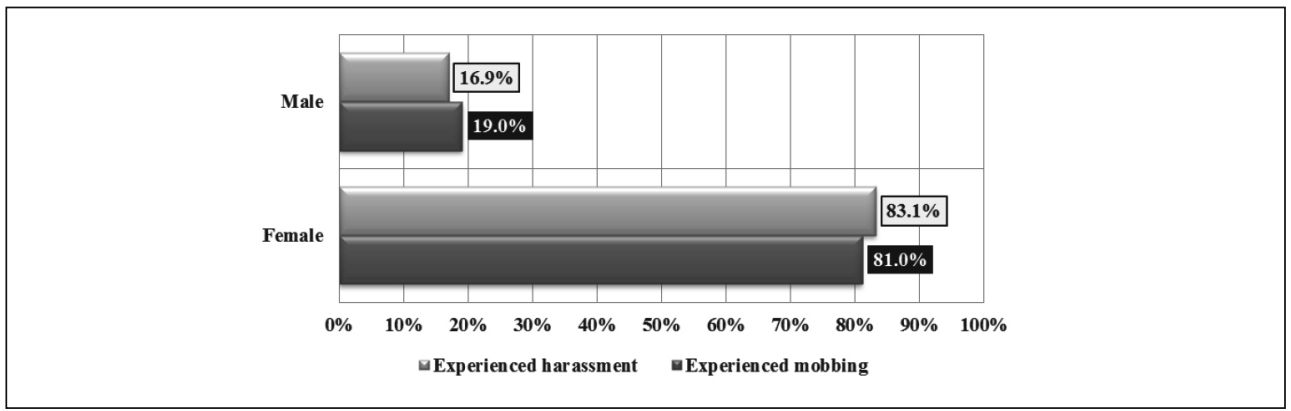

Source: own

\section{Fig. 4: Percentage distribution of respondents' answers according to their marital status}

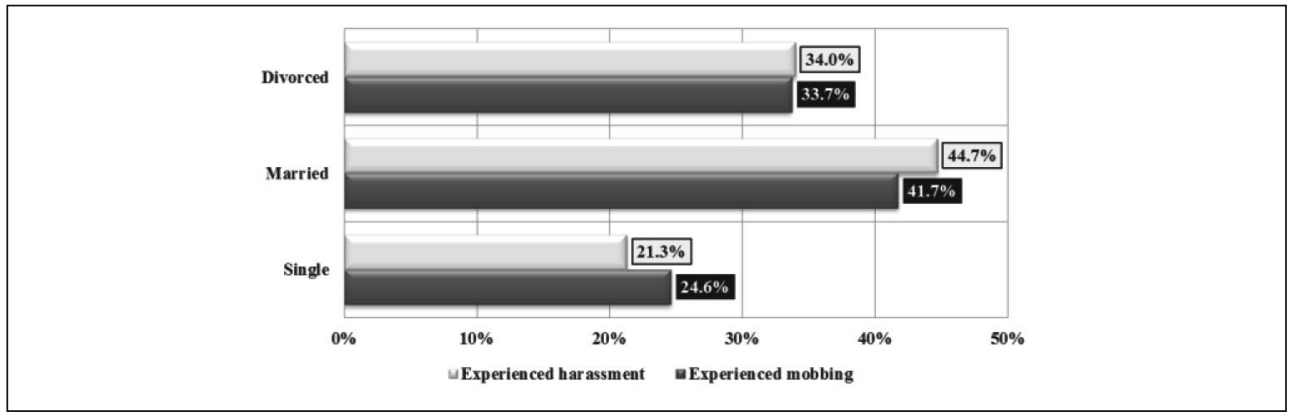

Source: own

Family in processes of attacks is highlighted as one of vulnerability zones, by social consequences of mobbing, and together it is one of the possibilities of help to the victims. Statistically significant differences between those who experienced mobbing and harassment according to the marital status have been found. It is shown by the research carried out. Waniorek and Warionek (1994) found that families of many of the victims break up, and Meschkutat et al. (2002) stressed the significance of the help of members of the family in dealing with conflicts of mobbing and minimizing their consequences. Therefore, the marital status is distinguished as one of the criteria in this research. In the case of this study, we can see that most of the victims of mobbing and harassment are persons who have families. In this research there were no questions whether the cause of divorce was mobbing, 
however it is significant that more than half of the respondents do not have a family, that is, they may lack support during the conflict of mobbing (Fig. 4). The comparison of the cases of harassment by the sector in which the victims work showed that almost two-thirds worked in the public sector. More than half of them have suffered mobbing. Although there was less mobbing and harassment in the private sector, but these phenomena swap the places. That is, there was more mobbing than bullying (Fig. 5).

Lithuanian public sector, compared with other EU countries, is still relatively young, but descriptions of positions and division of functions are not precise and clear, that provides additional possibilities to harass the victim in the workplace. According to Zapf (1999), the more uncertainty in the organizations is, the more possibilities for victimization are. In addition, the fact that such professional areas as education, health care, etc. where mobbing and harassment are more expressed, belong to the public sector was significant for more marked occurrence of mobbing and harassment. These data can be compared to the previous research (Žukauskas \& Vveinhardt, 2009): in state sector - 34.5, in private sector -65.5 . It was the first large scale research in Lithuania; until that very little was written of mobbing in both scientific and popular press of Lithuania. During that time, the level of public awareness of mobbing has changed dramatically, that allowed a more sensitive evaluation of the behaviour of colleagues. Another important factor is that the first survey was carried out before the economic crisis, during which organizations of the public sector experienced extremely strong restrictions. Educational organizations are experiencing a particularly strong uncertainty because of a declining number of pupils, closure of educational institutions and redundancy, which could have an impact on the fact that mobbing in the public sector is identified more frequently.

\section{Fig. 5: Percentage distribution of respondents' answers according to the sector}

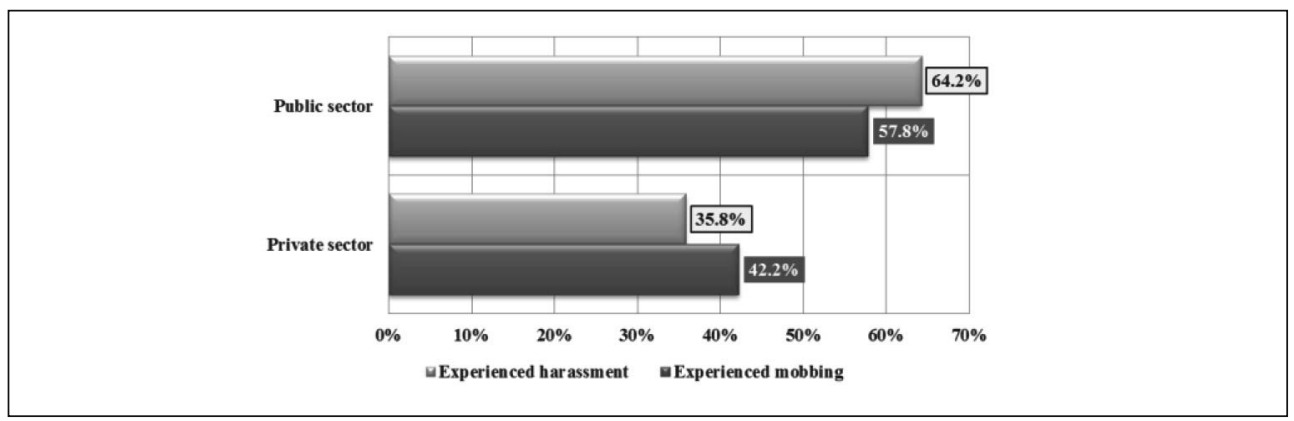

Source: own

\section{Fig. 6:}

Percentage distribution of respondents' answers according to the size of the organization

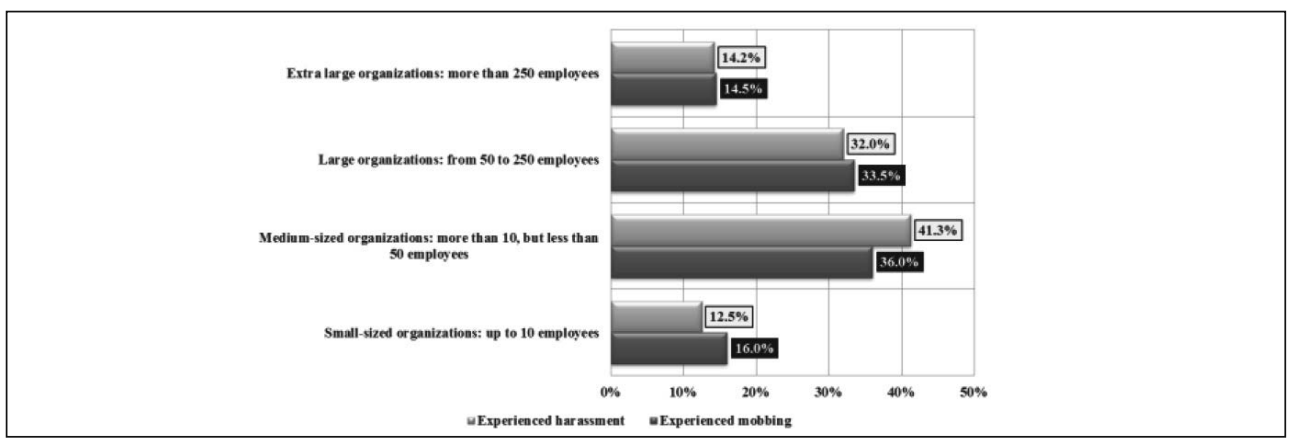

Experienced har assment axperienced mobbing 
About one third of the victims of mobbing worked in the medium-sized organizations and in large organizations. In small-sized and large organizations the occurrence of mobbing is several times lower. In extremely large organizations the percentage of harassment is equivalent to the percentage of the mobbing. On the basis of the results of the research carried out by Baillien et al. (2011), mobbing also seems more prevalent in small- and mediumsized enterprises without a people-oriented culture and in family businesses. However, it is relevant to evaluate cultural differences of populations of the different countries, but the lack of research in this area remains (Fig. 6).

In accordance with a position in the organization, two groups of employees who are most oppressed have formed. Mobbing was experienced by (per cent): the lowest level managers - 37.3, subordinates - 46.4. The lowest-level managers are often harassed and bullied by colleagues who have equal positions, only in very rare cases by subordinates; horizontal mobbing dominates in this group. Similar trends, with small percentage differences, are visible in cases of harassment as well.

All levels of management employees experience attacks in organizations, with some exceptions. The hired top managers are traditionally attacked by members of the boards of the companies. However, if a curve is drawn, ordinary employees, who are affected by both horizontal and vertical mobbing which expresses the misuse of available institutional power, find themselves on the peak in both cases of harassment and mobbing (Fig. 7).

\section{Fig. 7: Percentage distribution of respondents' answers according to positions}

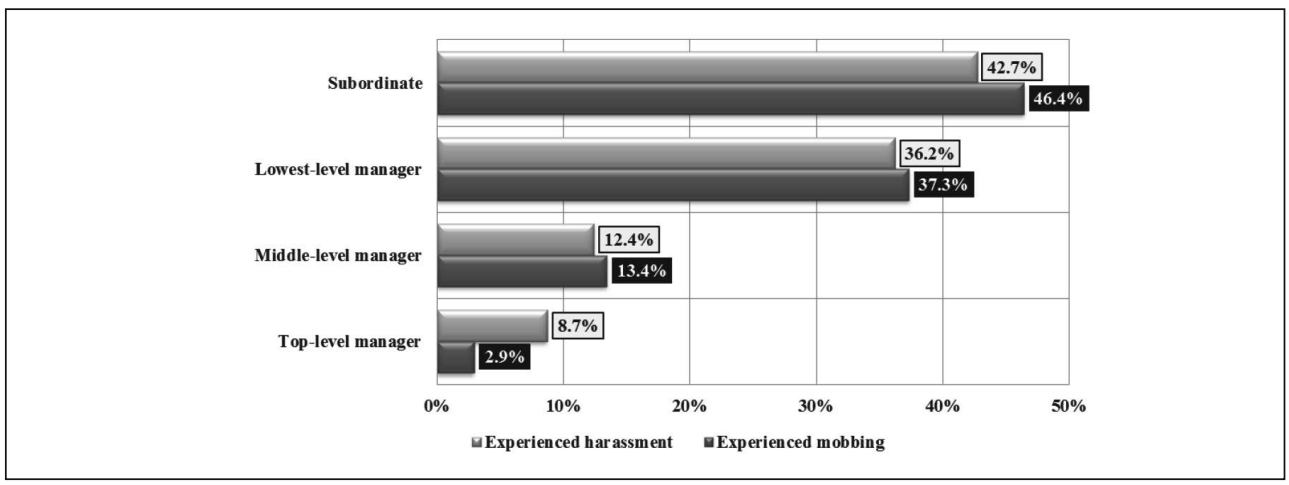

Source: own

In addition, the research has revealed that usually aggressors act jointly, with the awareness and support of managers, therefore, the victim experiences particular pressure (Fig. 7). The analysis has found $14.0 \%$ employees have suffered harassment from a co-worker, $22.1 \%$ from several co-workers. More than half $(63.9 \%)$ of the attackers are managers $(31.7 \%)$, managers and co-workers $(32.2 \%)$, so $31.7 \%$ and $32.2 \%$ respectively.

Even a third of the respondents say that the aggressor is one manager, therefore, the victims find themselves in a difficult situation.
Distribution of the victims who experienced harassment and mobbing according to the areas of professional activity is presented in Fig. 8, where education and administrative and service activities are distinguished most.

The lowest occurrence of mobbing and harassment is in professions that are more related to physical work (agriculture, mining and quarries exploitation, manufacturing, electricity, gas, steam supply and air conditioning). Leymann (1993), who distinguished agriculture, production, trade as areas of activity where mobbing is more rare, also found such a trend in early studies. 


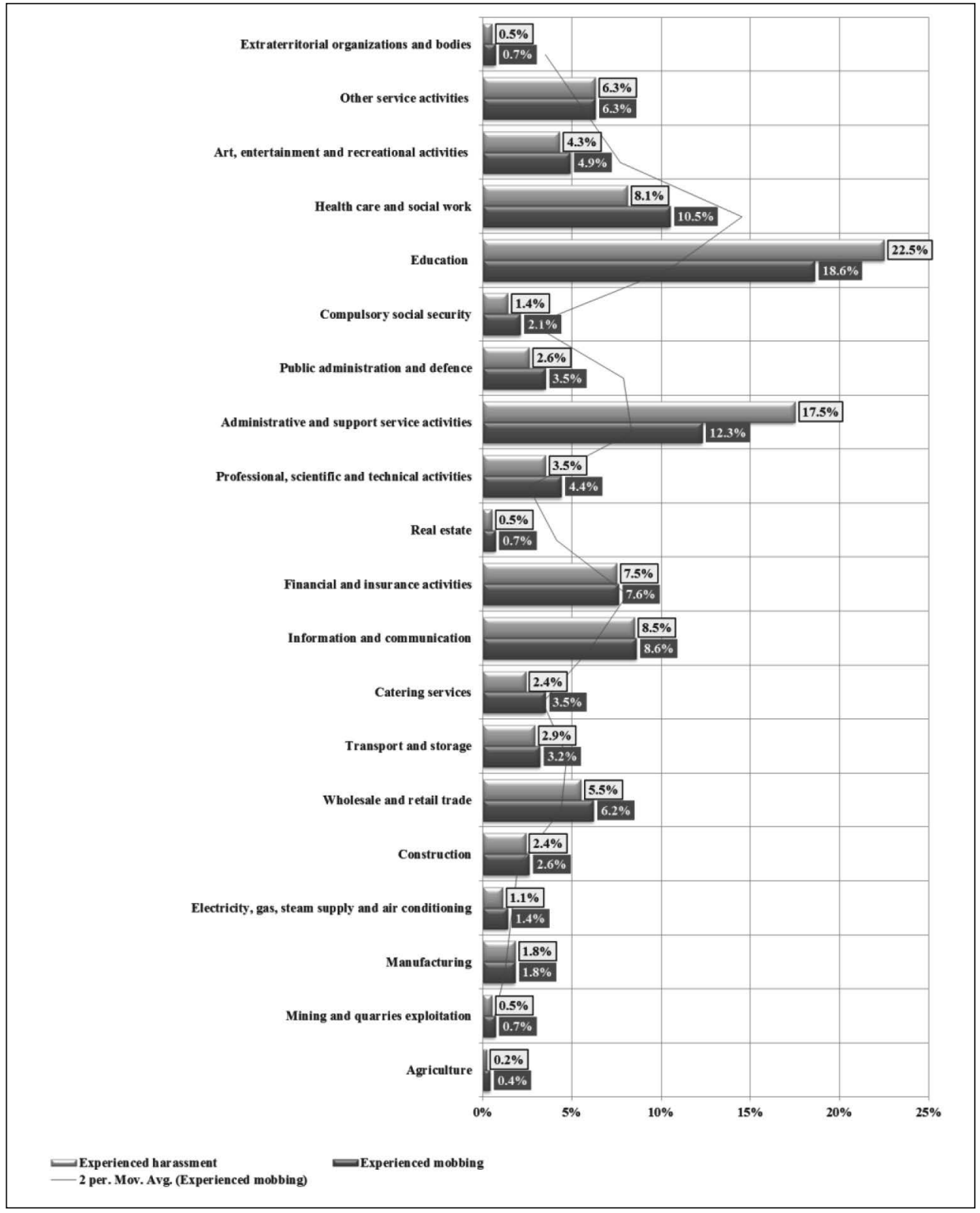


Thus, such areas of activity as education, health care and social work, information and communication, financial and insurance activities (from 7.6 to 18.6 per cent of those who have experienced mobbing) are distinguished. In other words, in organizations providing different services where employees have to communicate with clients more often. Moreover, these professions are distinguished by the fact that high education, competency requirements are set. Educational organizations are also markedly distinguished in previous studies carried out in Lithuania (Žukauskas \& Vveinhardt, 2013) both in respect of harassment that doesn't fall under the scheme of mobbing (according to the classical definition) and in respect of occurrence of mobbing. In addition, attention should be drawn to healthcare and social work (nursing care) $(10.5 \%)$. A relevant problem of mobbing in this area is also noted in studies carried out in other countries (Maclntosh et al., 2010; Waschgler et al., 2013).

\section{Fig. 9: Victims of mobbing and harassment according to education}

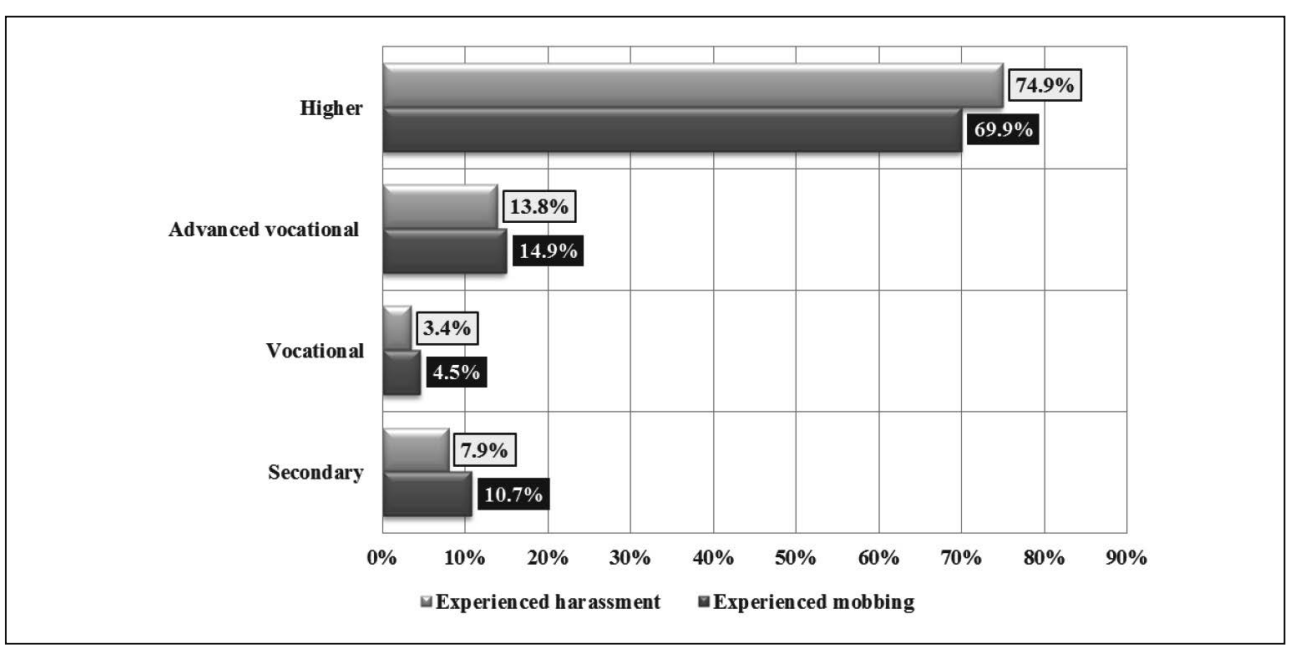

In addition, the occurrence of mobbing and harassment in education shows that representatives of this occupational area work in extremely difficult conditions, in the situation of a high level of conflict behaviour (Fig. 9).

In terms of education significant differences have been found among all four groups of employees both in the aspects of mobbing and harassment. The trend that the higher the respondents' level of education is, the more people who have experienced mobbing and harassment are, is highlighted. Inside the education groups no significant differences between harassment and mobbing have been found, but in the group of higher education, unlike the other three groups, harassment is more frequent than mobbing. Leymann (1993) has emphasised the fact that the frequency of mobbing is different depending on the occupational group. The studies carried out later have also found that mobbing is more frequent among those occupational groups which require higher education from employees (Leymann \& Gustafsson, 1996; Notelaers et al., 2013; etc.).

After the analysis of the socio-demographic portrait of the victim, the results of the research related to victim's reaction to harassment and the measures of help that have been provided to the victims are presented below.

The employees who have suffered from harassment and mobbing react to harassment differently. Fig. 10 shows the actions taken by the employees involved in the trap of destructive relationships.

The highest percentage of respondents who have experienced harassment share their 


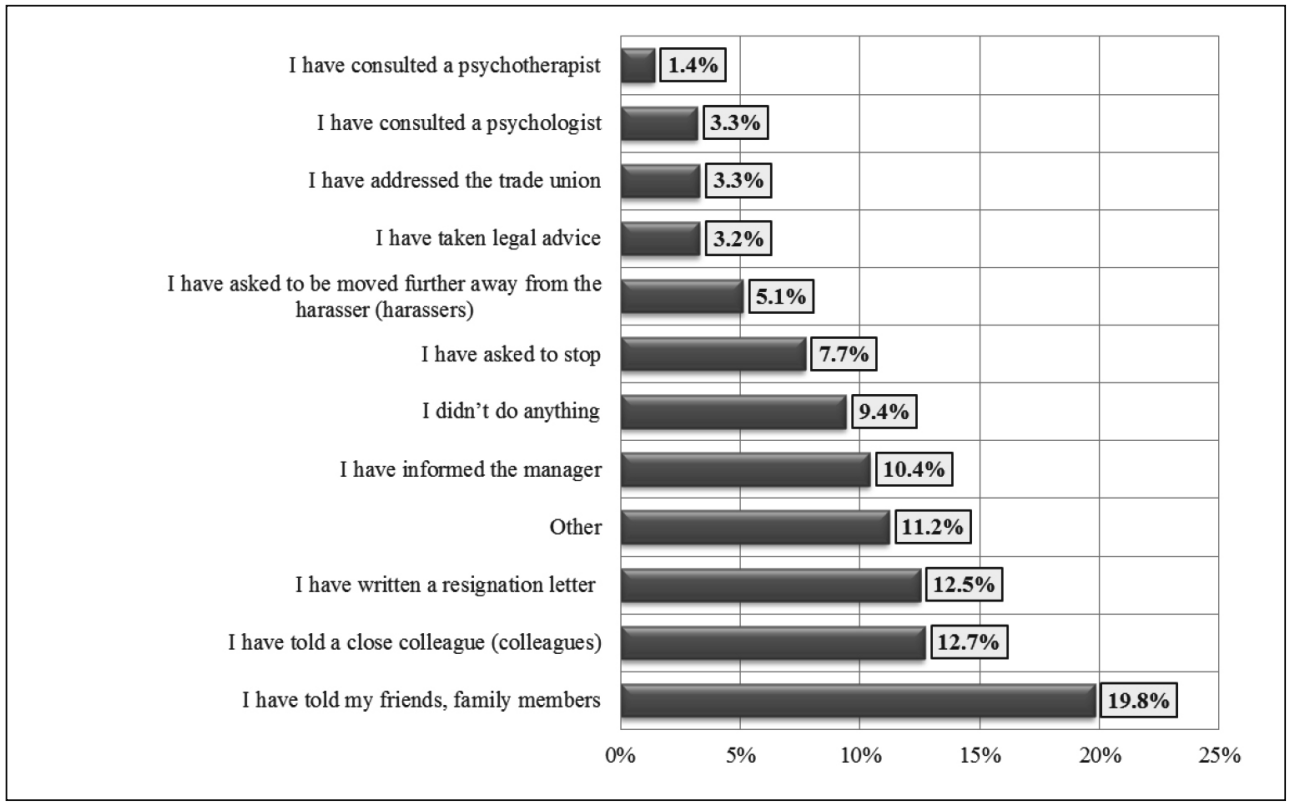

Source: own

feelings and bad experience at work only with friends and family members $(19.8 \%)$ that shows that only a close circle of people are the most reliable helpers, i.e., those who the victims of mobbing dare to tell about the problems at work. It is usual that the victims of mobbing consider themselves guilty in what is going on, therefore, they avoid talking about this with anyone at all.

Victims of mobbing frequently isolate themselves from any form of communication with colleagues, even those who do not contribute their actions to humiliating their co-workers. However, in case of this study it was found that a relatively high percentage of victims have a close colleague, who they trust to share their experiences $(12.7 \%)$.

This research was not aimed to determine at which stage of mobbing the victim leaves the workplace, however, on the basis of the results of the survey $(12.5 \%$ employees resign voluntarily), while planning further guidelines for research of mobbing in employee relations, it is clear that this question should be included in the questionnaire.

Those persons who took the opportunity to record explanation of their actions when filling in the questionnaire fall under the category of "other". Thus, the respondents, who selected the category "other", specified the following responses and/or actions: "I thought that the attacks against me are just temporary and they will soon stop, so I haven't told anything to anyone", "I haven't addressed anyone, because I didn't think that anyone could help me, the more so as I don't have any tangible evidence, only my personal experience", "I wrote a letter to the State Labour Inspectorate", etc.

The manager as a person who could provide the promptest and most effective help to the employee who suffers from harassment and mobbing should be the first person the employee contacts. However, the results of the research show that only one tenth of the victims of mobbing (10.4\%) turned for help to the managers. It may have been influenced by the fact that the managers themselves can often be "shadow" initiators of mobbing or on the initiative of the aggressors have been involved in the process of mobbing and poison others' mind against the victim, who is defined as: a person who doesn't perform the duties properly, who reacts to work situations 
inadequately and is negatively characterized in other ways. Finally, a part of the victims believe that the entire environment, as well as the manager, is set against them.

The victims of mobbing who opted to answer "I didn't do anything" (9.4\%) could be attributed to the staff, who just accept the current situation and quietly suffer abuse, don't know where to look for help, or they do not expect it. The victim's self-isolation is one of the consequences of mobbing.

One of the actions of victims of mobbing, a request to stop harassment, sounds like an appeal to the mind and the feelings of the harasser or mobber. The results of this research indicate that this action is not very common $(7.7 \%)$, the more so as it does not stop the aggressor's actions.

A very small percentage of the respondents $(5.1 \%)$ asked the management to be moved to another place, further away from harassers, but it is not physically possible to do this in every workplace, for example, in small companies.

When looking for help, the persons who have suffered from harassment turn to a psychologist or psychotherapist quite rarely (3.2\% and $1.4 \%$ respectively).

Addressing trade unions could receive a low percentage at least as a result of the fact that not in all areas of professional activity or separate organizations there are trade unions, on the other hand, if they exist, victims of mobbing frequently state that "it is useless to hope to get help from the trade unions because of their unwillingness to interfere in employees' relations", "trade unions are not completely independent from the head of the organization", "the chairperson of the trade union is close to the head of the organization", etc.).

And only as a last resort, when the victims of mobbing decide to fight using legal means, then they turn on the legal advice of the lawyer (attorney) (3.3\%).

\section{Fig. 11: Persons who have provided support and help to employees who suffered from harassment and mobbing}

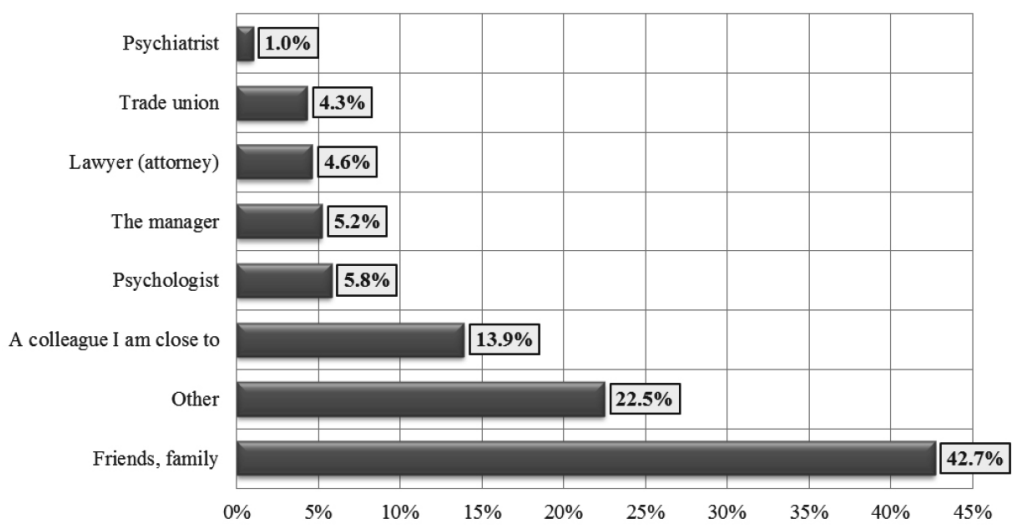

Source: own

Having found who the employees who have suffered from harassment and mobbing address, it has been tried to find out who of them helped the victim to deal with the situation at work. The category "other" indicates that people have unexpectedly received help from those who they did not ask: "the competing organization which found out from the surrounding what was going on, invited to work in their organization", "members of the religious community", "family doctor", etc.

The results of the research elaborated below show the consequences for the aggressor for his/her intolerable behaviour in the organization (Fig. 12). 


\section{Fig. 12: Consequences for the aggressor for intolerable behaviour in the organization}

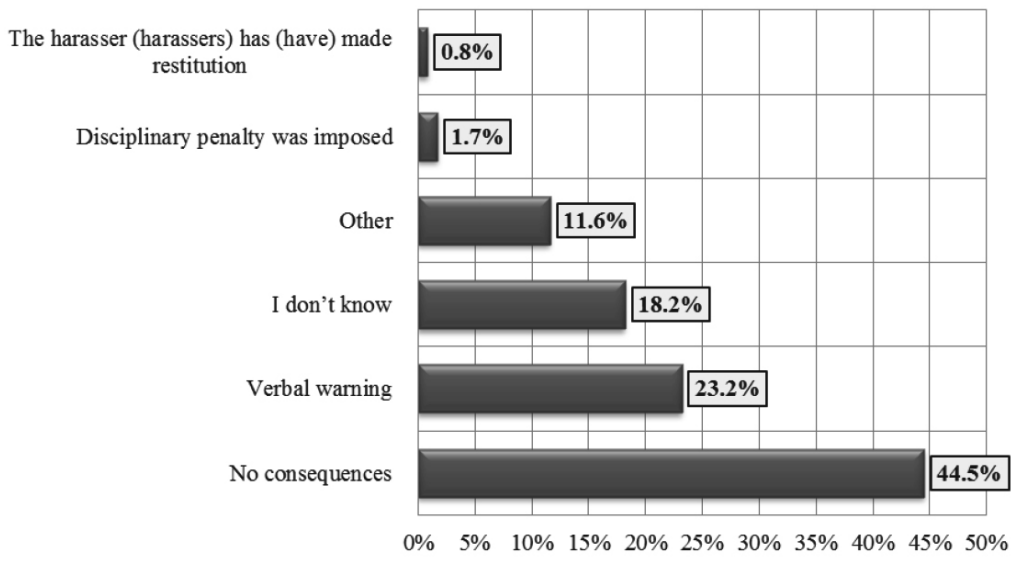

Source: own

Not a single respondent has chosen the categories of responses "Institutions of law enforcement have been informed" and "Administrative action or criminal prosecution was applied against a harasser (harassers)". It is not a usual practice in organizations to apply disciplinary and other forms of sanctions $(44.5 \%)$ to persons using harassment and mobbing or it is attempted to deal with the problem inside, without reporting to external authorities on offense against the person or persons. The most commonly used measure is a verbal warning to the harasser, which according to the laws of the Republic of Lithuania is not even attributed to disciplinary measures; therefore, it does not have any consequences that the measures of disciplinary action in written form have. 18.2 percent of the victims did not receive any information about the measures taken, that is, there is no sufficient feedback, and the victims remain in a state of uncertainty and continue to suffer fear and other negative feelings.

Such cases, when the harasser has made restitution of damage to the victim or has received a verbal warning are extremely rare $(0.8 \%$ and $1.7 \%$ respectively). Such consequences to the aggressor as "after talking to the manager it has become even worse", "I have been moved to another department", "I was offered to write a letter of resignation", etc. have been named in the category "other" on this question. That is, the victim who was seeking help was suffering; instead of preventing harassment, support to the harasser was expressed, thus encouraging further negative behaviour in the future.

After finding out what the consequences for the aggressor were, the aim was to determine whether the organization / the manager have taken any preventive measures so that harassment and mobbing would not occur again. The questionnaire included statements that capture actions of the organization that demonstrate publicity, intolerance of harassment and mobbing, as well as measures to increase social competence of employees, enabling them to respond properly to the aggressor's attacks. Almost two thirds of respondents said that on the level of the organization there was no discernible reaction - no public action aimed at prevention of the negative behaviour in the future has been taken. None of the respondents indicated that a professional consultant was invited, and only in 0.5 percent of all responses indicate that the training was held. This means that organizations do not perceive and evaluate the damage of this specific negative behaviour and risks posed to employees by an aggressor adequately. If some of the measures are used (the situation made public, discussed with 
The seminar aimed at prevention of harassment at the workplace has been held

The situation was given publicity in the organization as an intolerable example

The situation has been discussed with colleagues

The management has publicly demonstrated intolerance of harassment

No actions have been made

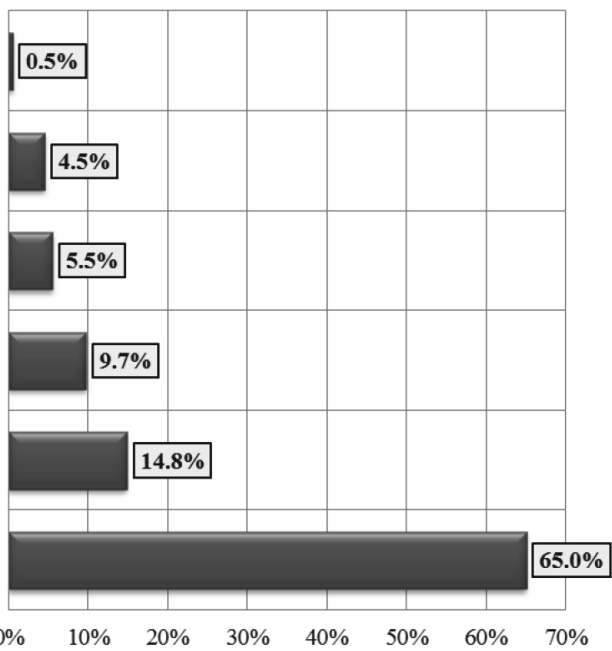

\section{Fig. 14: Prevention/intervention measures applied in organizations}

Bullying and harassment are discussed in the code of ethics, which is followed

The specialist who renders psy chological and other assistance is available

Trainings and seminars, where it is explained how to avoid psychological and physical violence and / or how to behave when a.. Bullying and harassment are discussed in the collective agreement

During the employment process, psychological tests were applied Bullying and harassment are discussed in the code of ethics; however, it is not followed

Colleagues always render their assistance

No attention has been given to mobbing and harassment in the collective agreement

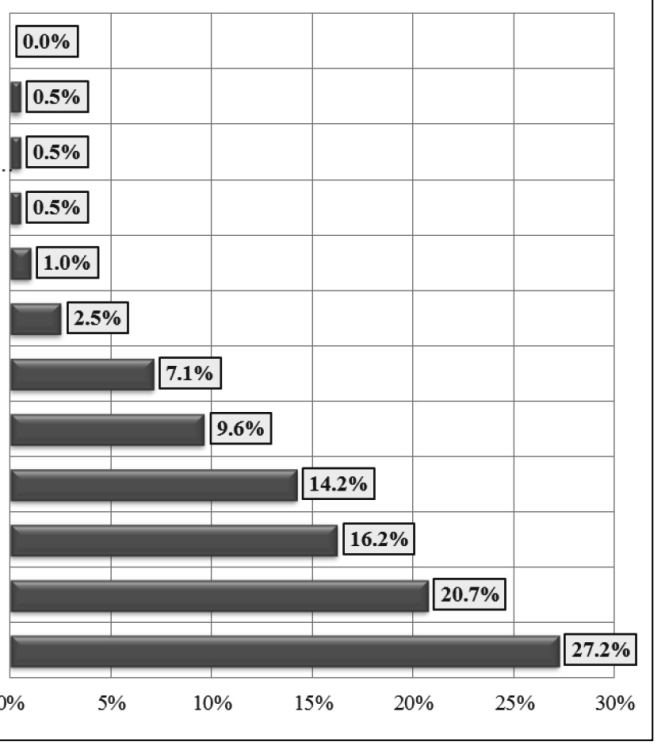

You can always address the manager if you have experienced bullying and harassment

Colleagues are indifferent or support the harasser

It is useless to address the manager if you had experienced bullying and harassment

Source: own 
co-workers), they are used at the minimum, therefore, they cannot be considered as adequate and effective (Fig. 13).

The lack of attention of the organization / the management is proved by Fig. 14 that reflects the organizational policy on harassment and mobbing.

The fact that only $7.1 \%$ of the respondents indicated that in case of an attack one can always expect the colleagues' support, while a significantly greater part of employees are indifferent or support the aggressor can be considered to be a consequence of this indifferent policy. The fact that $27.2 \%$ of employees are certain that in the event of mobbing and harassment it is pointless to address the manager is significant. These provisions virtually give a signal on the wrong policies of the organizations, which in principle do not provide an opportunity to discuss mobbing and harassment in the collective agreements and the codes of ethics. All of this creates a threatening environment and poses a great risk that the employees may become victims of harassment and mobbing and may not receive prompt and effective aid.

\section{Conclusions}

This research provides new additional sociodemographic data on the occurrence of mobbing in the public and private sector organizations. The extent of the risk to suffer harassment and mobbing is associated with such criteria as the employee's age, period of the career, position in the hierarchy of the organization, education, the size of the company and the sector of activity. Two largest risk zones of mobbing and harassment related to the age and length of service are highlighted: the first and largest one is a start of professional career; the second is the preretirement age. Professional activities of education, administration and services, where the expression of negative behaviour was the largest, was distinguished in the inner structure of those who experienced harassment and mobbing. In addition, the obtained result, opposite to some studies, indicates that employees of public sector organizations are less protected from the aggression of colleagues than in the private sector. However, harassment in the companies of the private sector can take a more aggressive and intense form of mobbing.
The organizational weakness of both private and public sectors in the protection of employees against the co-workers' aggression and in eliminating it has been revealed. The more so as the sociodemographic picture of the victims indicates that a significant part of employees has limited opportunity to get support in the near environment.

The results of the research show the influence of sociodemographic criteria both on harassment and mobbing, thus, both the research of unethical actions, aggression in the workplace and the organization of prevention should not be limited to one narrower aspect. In addition, it provides the reason to revise the instruments of mobbing research in the future, as the strict application of the formula "at least once a week and for at least six months" does not include all the cases with the obvious features of mobbing, and can provide a not quite accurate picture. This means that the extent of the prevalence of mobbing may be greater than is recorded.

This research does not show the prevalence of harassment and mobbing in the aspect of all the population and reveals only the inner structure of those who experienced negative colleagues' actions in the context of one of the organizations of the country. For broader generalizations the research should be repeated in the future in different countries and the data should be compared.

\section{References}

Adikaram, A. S. (2014). "Good women" and "bad women": how socialization of gendered behavioural norms influences Sri Lankan working women's interpretation of sexual harassment at workplaces. South Asian Journal of Human Resources Management, 1(1), 45-65. doi:10.1177/2322093714526662.

Baillien, E., Neyens, I., \& De Witte, H. (2011). Organizational correlates of workplace bullying in small- and medium-sized enterprises. International Small Business Journal, 29(6), 610-625. doi:10.1177/0266242610375774.

Beirne, M., \& Hunter, P. (2013). Workplace bullying and the challenge of preemptive management. Personnel Review, 42(5), 595-612. doi:10.1108/PR-07-2012-0105.

Brodsky, C. M. (1976). The Harassed Worker. Toronto: Lexington Books, DC Heath and Company. 
Carnero, M. A., Blanca Martínez, B., \& Mangas, R. S. (2012). Mobbing and workers' health: empirical analysis for Spain. International Journal of Manpower, 33(3), 322-339. doi:10.1108/01437721211234183.

Casimir, G., McCormack, D., Djurkovic, N., \& Nsubuga-Kyobe, A. (2012). Psychosomatic model of workplace bullying: Australian and Ugandan schoolteachers. Employee Relations, 34(4), 411-428. doi:10.1108/01425451211236841.

Chrobot-Mason, D., Ragins, B. R., \& Linnehan, F. (2013). Second hand smoke: ambient racial harassment at work. Journal of Managerial Psychology, 28(5), 470-491. doi:10.1108/JMP-02-2012-0064.

Citoni, G., Mahy, B., \& Rycx, F. (2012). Work organization, performance and health: introduction. International Journal of Manpower, 33(3), 224-232. doi:10.1108/01437721211234129.

Classification of Economic Activities. (2008). Statistics Lithuania, available at: http://web.stat. gov.lt/uploads/klasifik/EVRK/EVRK2red_It.htm.

Cooper-Thomas, H., Gardner, D., O'Driscoll, M., Catley, B., Bentley, B., \& Trenberth, L. (2013). Neutralizing workplace bullying: the buffering effects of contextual factors. Journal of Managerial Psychology, 28(4), 384-407. doi:10.1108/JMP-12-2012-0399.

D'Cruz, P., \& Rayner, C. (2013). Bullying in the Indian workplace: a study of the ITES-BPO sector. Economic and Industrial Democracy, 34(4), 597-619. doi:10.1177/0143831X12452672.

Daigle, L. E., \& Mummert, S. J. (2014). Sex-role identification and violent victimization: gender differences in the role of masculinity. Journal of Interpersonal Violence, 29(2), 255-278. doi:10.1177/0886260513505148.

Einarsen, S. (1999). The nature and causes of bullying at work. International Journal of Manpower, 20(1/2), 16-27. doi:10.1108/01437729910268588.

Einarsen, S. (2005). The nature, causes and consequences of bullying at work: the Norwegian experience. Pistes, 7(3), 1-16. doi:10.4000/pistes.3156.

Einarsen, S., \& Skogstad, A. (1996). Bullying at work: epidemiological findings in public and private organizations. European Journal of Work and Organizational Psychology, 5(2), 185-201. doi:10.1080/13594329608414854.
Ertürk, A., \& Cemaloğlu, N. (2014). Causes of mobbing behavior. Social and Behavioral Sciences, 116, 3669-3678. doi:10.1016/j.sbspro.2014.01.821.

Ford, D. P. (2013). Virtual harassment: media characteristics' role in psychological health. Journal of Managerial Psychology, 28(4), 408-428. doi:10.1108/JMP-12-2012-0398.

Hacicaferoglu, S., Gundogdu, C., Yucel, A. S., \& Acet, M. (2012). Examination of mobbing behaviors experienced by the personnel working at youth services and provincial directorates of sports. International Journal of Academic Research, 4(2), 5-10.

Hoel, H., Zapf, D., \& Cooper, C. L. (2002). Workplace Bullying and Stress. In P. L. Perrewe, \& D. C. Ganster (Eds.), Research in Occupational Stress and Well Being (Vol. 2, pp. 293-333). Amsterdam: JAI.

Hogh, A., Mikkelsen, E. G., \& Hansen, A. M. (2011). Individual consequences of Workplace Bullying/Mobbing. In S. Einarsen, H. Hoel, D. Zapf, \& C. L. Cooper (Eds.), Bullying and Harassment in the Workplace: Developments in Research, and Practice (2nd ed., pp. 107-128). Boca Raton: C R C Press LLC.

Holt, T. J., Fitzgerald, S., Bossler, A. M., Chee, G., \& Ng, E. (2014). Assessing the risk factors of cyber and mobile phone bullying victimization in a nationally representative sample of Singapore youth. International Journal of Offender Therapy and Comparative Criminology, 60(5), 598-615. doi:10.1177/0306624X14554852.

Huang, L. Y., \& Cao, L. (2008). Exploring sexual harassment in a police department in Taiwan. Policing: An International Journal of Police Strategies \& Management, 31(2), 324-340. doi:10.1108/13639510810878758.

Hutchinson, J. (2012). Rethinking workplace bullying as an employment relations problem. Journal of Industrial Relations, 54(5), 637-652. doi:10.1177/0022185612454955.

Hutchinson, M., \& Jackson, D. (2015). The construction and legitimation of workplace bullying in the public sector: insight into power dynamics and organisational failures in health and social care. Nursing Inquiry, 22(1), 13-26. doi:10.1111/nin.12077.

Jacobson, K. J. L., Hood, J. N., \& Van Buren III, H. J. (2014). Workplace bullying across cultures: a research agenda. International Journal of Cross Cultural Management, 14(1), 47-65. doi:10.1177/1470595813494192. 
Johnson-Bailey, J. (2014). Academic incivility and bullying as a gendered and racialized phenomena. Adult Learning, 26(1), 42-47. doi:10.1177/1045159514558414.

Karatuna, I. (2015). Targets' coping with workplace bullying: a qualitative study. Qualitative Research in Organizations and Management: An International Journal, 10(1), 21-37. doi:10.1108/QROM-09-2013-1176.

Kaya, G., Ahi, B., \& Tabak, H. (2012). Primary Education Teacher's Problem: Mobbing (Kastamonu Province Sample). Procedia Social and Behavioral Sciences, 46, 838-842. doi:10.1016/j.sbspro.2012.05.209.

Koeszegi, S. T., Zedlacher, E., \& Hudribusch, R. (2014). The war against the female soldier? The effects of masculine culture on workplace aggression. Armed Forces \& Society, 40(2), 226-251. doi:10.1177/0095327X12460019.

Leymann, H. (1990). Mobbing and Psychological Terror at Workplaces. Violence and Victims, 5(2), 119-126.

Leymann, H. (1993). Mobbing: Psychoterror am Arbeitplatz und wie man sich dagegen wehren kann. Reinbek bei Hamburg: Rowohlt Taschenbuch verlag.

Leymann, H., \& Gustafsson, A. (1996). Mobbing and the post-traumatic stress disorders. European Journal of Work and Organisational Psychology, 5(2), 251-276. doi:10.1080/13594329608414858.

Macdermott, T. (1995). The duty to provide a harassment-free work environment. Journal of Industrial Relations, 37(4), 495-523. doi:10.1177/002218569503700401.

Maclntosh, J., Wuest, J., Gray, M. M., \& Aldous, S. (2010). Effects of workplace bullying on how women work. Western Journal of Nursing Research, 32(7), 910-931. doi:10.1177/0193945910362226.

Mathisen, G. E., Øgaard, T., Einarsen, S. (2012). Individual and situational antecedents of workplace victimization. International Journal of Manpower, 33(5), 539-555. doi:10.1108/01437721211253182.

Mauno, S., De Cuyper, N., Kinnunen, U., \& De Witte, H. (2011). Work characteristics in long-term temporary workers and temporary-topermanent workers: a prospective study among Finnish health care personnel. Economic and Industrial Democracy, 33(3), 357-377. doi:10.1177/0143831X11408939.

Meschkutat, B., Stackelbeck, M., \& Lagengoff, G. (2002). Der Mobbing-Report.
Repräsentativstudie für die Bundesrepublik Deutschland. Schriftenheire der Bundesansstalt für Arbeitsschutz und Arbeitsmedizin Forscung, Fb 951 (2 Auflage). Bremerhaven: Wirtschaftsverlag NM.

Moreno-Jiménez, B., Muñoz, A., Salin, D., \& Morante-Benadero, M. (2008). Workplace bullying in Southern Europe: prevalence, forms and risk groups in a Spanish sample. International Journal of Organisational Behaviour, 13(2), 95-109.

Muliawan, H., \& Kleiner, B. H. (2001). African American perception of sexual harassment. Equal Opportunities International, 20(5/6/7), 53-58. doi:10.1108/02610150110786732.

Niedl, K. (1995). Mobbing/Bullying am Arbeitzplaz-Mobbing/Bullying at the work place. Eine Empirische Analyse zum Phaenomen sowie zu personalwirtschaftlich relevanten Effekten von systematischen Feindseiligkeiten. Personalwirtschafliche Schriften, Muenchen: Rainer Hampp Verlag.

Notelaers, G., Baillien, E., De Witte, H., Einarsen, S., \& Vermunt, J. K. (2013). Testing the strain hypothesis of the Demand Control Model to explain severe bullying at work. Economic and Industrial Democracy, 34(1), 69-87. doi:10.1177/0143831X12438742.

O'Donnell, S. M., \& Macintosh, J. A. (2015). Gender and workplace bullying: men's experiences of surviving bullying at work. Qualitative Health Research, 26(3), 351-366. doi:10.1177/1049732314566321.

Picakciefe, M., Acar, G., Colak, Z., \& Kilic, I. (2015). The relationship between sociodemographic characteristics, work conditions, and level of "mobbing" of health workers in primary health care. Journal of Interpersonal Violence, 32(3), 373-398. doi:10.1177/0886260515586360.

Riley, D., Duncan, D. J., \& Edwards, J. (2011). Staff bullying in Australian schools. Journal of Educational Administration, 49(1), 7-30. doi:10.1108/09578231111102036.

Salin, D. (2009). Organisational responses to workplace harassment: an exploratory study. Personnel Review, 38(1), 26-44. doi:10.1108/00483480910920697.

Salin, D., \& Hoel, H. (2013). Workplace bullying as a gendered phenomenon. Journal of Managerial Psychology, 28(3), 235-251. doi:10.1108/02683941311321187.

Salin, H. (2003). Ways of explaining workplace bullying: a review of enabling, 


\section{Ekonomika a management}

motivating and precipitating structures and processes in the work environment. Human Relations, 56(10), 1213-1232. doi:10.1177/00187267035610003.

Sedivy-Benton, A., Strohschen, G., Cavazos, N., \& Boden-McGill, C. (2014). Good ol' boys, mean girls, and tyrants: a phenomenological study of the lived experiences and survival strategies of bullied women adult educators. Adult Learning, 26(1), 35-41. doi:10.1177/1045159514558411.

Stedham, Y. E., \& Yamamura, J. H. (2004). Measuring national culture: does gender matter? Women in Management Review, 19(5), 233-243. doi:10.1108/09649420410545953.

Waniorek, L., \& Waniorek, A. (1994). Mobbing: Wenn der Arbeitsplatz zur Holle wird. Muenchen: Mvg-Verlag.

Waschgler, K., Ruiz-Hernández, J. A., Llor-Esteban, B., \& Jiménez-Barbero, J. A. (2013). Vertical and Lateral Workplace Bullying in Nursing: Development of the Hospital Aggressive Behaviour Scale. Journal of Interpersonal Violence, 28(12), 2389-2412. doi:10.1177/0886260513479027.

Yildirim, D., Yildirim, A., \& Timucin, A. (2007). Mobbing behaviors encountered by nurse teaching staff. Nursing Ethics, 14(4), 447-463. doi:10.1177/0969733007077879.
Zapf, D. (1999). Organisational, work group related and personal causes of mobbing/bullying at work. International Journal of Manpower, 20(1/2), 70-85. doi:10.1108/01437729910268669.

Zemke, R., Raines, C., \& Filipczak, B. (2000). Generations at Work: Managing the Clash of Veterans, Boomers, Xers and Nexters in Your Workplace. New York: Amacon.

Žukauskas, P., \& Vveinhardt, J. (2009). Socio-demographic characteristics of mobbing and discrimination in employee relations. Transformations in Business and Economics, 8(3), suppl. A, 129-147.

Žukauskas, P., \& Vveinhardt, J. (2013). Mobbing and bullying within the organization: socio-demographic portrait of the victim. Krytyka Prawa-Critique of Law, 5(1), 693-716. doi:10.7206/kp.2080-1084.35.

Prof. Dr. Jolita Vveinhardt Vytautas Magnus University Faculty of Economics and Management Department of Management jolita.vveinhardt@gmail.com

Prof. Dalia Štreimikienè, Ph.D. Chief Researcher Vilnius University Kaunas Faculty dalia.streimikiene@Isu.It 


\title{
Abstract
}

\section{DEMOGRAPHIC, SOCIAL AND ORGANIZATIONAL CHARACTERISTICS ONTHE LEVELS OF MOBBING AND SINGLE CASES OF HARASSMENT: THE MULTICOMPLEX APPROACH}

\author{
Jolita Vveinhardt, Dalia Štreimikienè
}

The article deals with demographic, social and organizational characteristics of mobbing and single cases of harassment. Many papers analyze these characteristics separately. However, according to the authors of this article, it is necessary to evaluate a wide context of workplace mobbing and single cases of harassment to determine the factors affecting the occurrence of the phenomenon. The multi-complex approach to the influencing conditions is necessary for corporate managers, making preventive and intervention decisions.

The research was carried out using the validated questionnaire "The occurrence of mobbing and single cases of harassment in relations between employees" in the private and public sector organizations of Lithuania. 1,231 respondents, who experienced violence in mutual relations, were surveyed. 867 employees distinguished from the respondents experienced mobbing, and 364 employees experienced single cases of harassment.

The results of this research explain the spread of mobbing and single cases of harassment in organizations of different sizes and types, its dynamism. They also allow showing that the unmanaged process has a tendency to intensify over time. Two largest risk zones of mobbing and single cases of harassment related to the age and length of service have been highlighted: the first and largest one is a start of professional career; the second is the pre-retirement age. Marital status doesn't have any statistically significant influence on becoming a victim of mobbing and single cases of harassment, although a slightly higher number of victims, who are divorced or haven't created a family, were found. The relationship between the size of the organization and the occurrence of mobbing and single cases of harassment was found. The position of the victim of harassment and mobbing in the organization is conditioned by systemic causes related to internal conditions determined by the organizational policy.

The article presents only a part of the research results. This part of the research allows the formation of socio-demographic view of the victim of mobbing and single cases of harassment in the organization, distinguishing the influencing factors under individual characteristics. The research was conducted only in one country, so the data should be tested by the cases of other countries.

Key Words: Mobbing, single cases of harassment, socio-demographic criteria, organizational criteria, destructive relations between employees.

JEL Classification: M12, M14, M19.

DOI: 10.15240/tul/001/2017-3-004 